\title{
Application of Drones for Agricultural Processes: its Challenges and Way-Forward
}

\author{
V. Essien ${ }^{1}$, J. Azeta $^{1}$ *, C. A. Bolu ${ }^{1}$, and I. P. Okokpujie ${ }^{1}$ \\ ${ }^{1}$ Department of Mechanical Engineering, Covenant University, Ota, Ogun State, Nigeria \\ Corresponding Author; joseph.azeta@ covenantuniversity.edu.ng
}

\begin{abstract}
Precision agriculture is becoming more relevant in the contemporary world to reduce and cut waste in agricultural resources. Drones have importantly contributed to crop protection, monitoring, and output, so the contribution and utilization of drones for agrarian tasks are no longer unnoticed. Africa has enormous landmass, but due to lack of advanced technology, these vast hectares of land produce little. However, one of the sustainable development goals is the total eradication of hunger by 2030 , which will seek to employ better and improved means for crop production processes. Drones have not been fully exploited, especially in Africa, to use manual labour for agricultural purposes. This paper carefully review and analyses the various areas where drones can be appropriately applied as well as some specific characteristics associated with drones.
\end{abstract}

Key words: autonomous quad-copter, crop monitoring, degree of autonomy, drones, precision agriculture

\section{INTRODUCTION}

In the early 1980s, drones were made commercial, and its use and relevance in agriculture remain unlimited as a result of its wide variety of applications. The use of drones in agriculture includes and is not limited to crop monitoring and survey, livestock inspection, and wide ranges of other applications. However, the full potential of using a drone in agriculture has not been exploited [1]. Africa as a continent is vast with various agro-ecological zones, but just then, the agricultural output is not proportional to the enormous abundance of landmass available in the continent [2]. As a result of agriculture, favorable climatic conditions [2], the continent invariably should be able to grow and provide food for other continents and individual countries. However, studies have shown that Africa has been lagging in crops and animal production compared with different continents in the world [3], [4]. There are seventeen sustainable development goals to transform the world, and one of them is the zero hunger policy. Extreme hunger remains a significant problem ravaging the continent as it serves as a barrier to development

[5]. The SDG aims to eradicate all forms of hunger and malnutrition totally in the year 2030. African leaders have also intensified efforts and strengths in finding long-lasting, sustainable solutions to hunger. Working simultaneously with the African Development Bank and the U.N. Economic Commission for Africa, the Comprehensive Agriculture Development Programme incorporated in 2013 [6]. It remains evident that technology will be the dominant platform to drive and improve significantly in the agricultural sector. The autonomous quad-copter UAV will fit considerably in performing the various functions in this field. There are remotely automated quad-copter UAVs, and some are semi-automated while research is still ongoing to develop a fully automated drone. With the vast expanse of landmass for agriculture in Africa, an autonomous quad-copter UAV will cover a large area of land within a short period compared to a manual survey carried out by the farmer.

\section{DRONES AND IT'S APPLICATION}

Table 1 shows a summary of different research work on the application of drones for both agricultural systems and any other sub-systems. 
V. Essien et al., International Journal of Emerging Trends in Engineering Research, 8(10), October 2020,7712 - 7717

Table 1. Summary of Different Applications of Drone for General and Specific Functions

Author Study

Findings

[7] The study analysis here featured a prototype with a larger VMD droplet size while focusing on crop production management emphasis on an increased target rate.

[8] This study carefully analysed how usage of drones reduces wastage of agricultural resources

[9] Carefully analysed different control techniques considering control architecture and control methods - utilization in putting out a forest fire.

[10] UAVs invariably can be used to monitor plant growth and also detect yield variability with careful attention paid to the displayed image.

[11] Aerial satellite imagery used in determining the yield of irrigated potato fields

[12] UAV for crop monitoring and pesticide spraying

[13] 6DOF Control system for an autonomous quad-copter.

[15] Foldable frame design to transport quad-copter safely

[16] A reference for the optimized design, performance upgrade and reasonable application of small UAV sprayers

[17] A reference for designing multi-rotor UAV electrostatic spray devices

[18] Design of a quadrotor unmanned vehicle capable of autonomous flight

[19] Study of the various kinds and concepts of autonomy from fully autonomous to semi-autonomous

[20] Research on the use of drones in precision agriculture.

[21] Photogrammetric mapping using an unmanned aerial vehicle

This study focused on the technical review of applications of UAVs in agriculture.

[23] This study specifically focused on how UAVs can be used for crop protection.
This research did not meet the low volume sprayer capability. An excess spray of these pesticides

UAVs used here for essential accurate use of farm resources

The control architecture determines how well the components communicate with each other.

The accurate analysis from the imagery defects crop diseases accurately without any further software analysis.

Image quality was not clear enough to identify key features

No low volume sprayer

The more degrees of freedom, the more a drone can easily navigate and move around with ease.

Modelling techniques are analyzed in this paper as well as key applications with specific characteristic relevant in various operations.

Could not perform any engineering operation Adaptation of a low volume sprayer for precision agriculture.

The size and weight of a drone are a characteristic that has to be considered as it affects the drone's overall performance.

The various degrees of autonomy were analysed here.

The various degrees of autonomy were discussed and analysed here.

Drones are very effective when it comes to getting accurate measurements of agricultural resources used per time

Drones installed with a photogrammetric map like the (NVDI) makes navigation and survey easy.

The paper highlights the major specific applications of unmanned aerial vehicles.

Drones can be used to find out when a particular plant is defective and also makes the farmer aware of the pest and possible weeds competing with the plants. 
V. Essien et al., International Journal of Emerging Trends in Engineering Research, 8(10), October 2020,7712 - 7717

Autonomous unmanned aerial vehicles for agricultural application.

Drones for Parcel and Passenger transportation.

[26]

The information and communication advancement was analyzed in this paper with various innovative techniques developed over the years in achieving this feat.

[27]

The digital frontiers of fisheries governance: fish attraction devices, drones and satellites.
UAVs were explicitly used for crop monitoring.

The various barriers associated with this new line of drone application was discussed in this paper. It further discusses prospects with regards to traffic reduction and public awareness of drone benefits.

Drones were highlighted here as being highly suitable for the new trends in achieving fast scale farming operations.

This paper highlights the use of drones in marine surveillance, being able to capture aerial views of illegal activities in marine habitat.
The building blocks as proposed by Krishnan et al., 2020 [28] on agricultural technology in figure 1 highlights the various hardware components and equipment that were used. This further gives rise to the software embedded into the system. The hardware and software together translates to the data chains comprising of the data marketing, data analysis, data transformation, data transfer, data storage and the data capture. This then goes through the process of assimilation and then to the monitoring and evaluation feedback. The hardware, software and data chains are inter-dependent on each other.

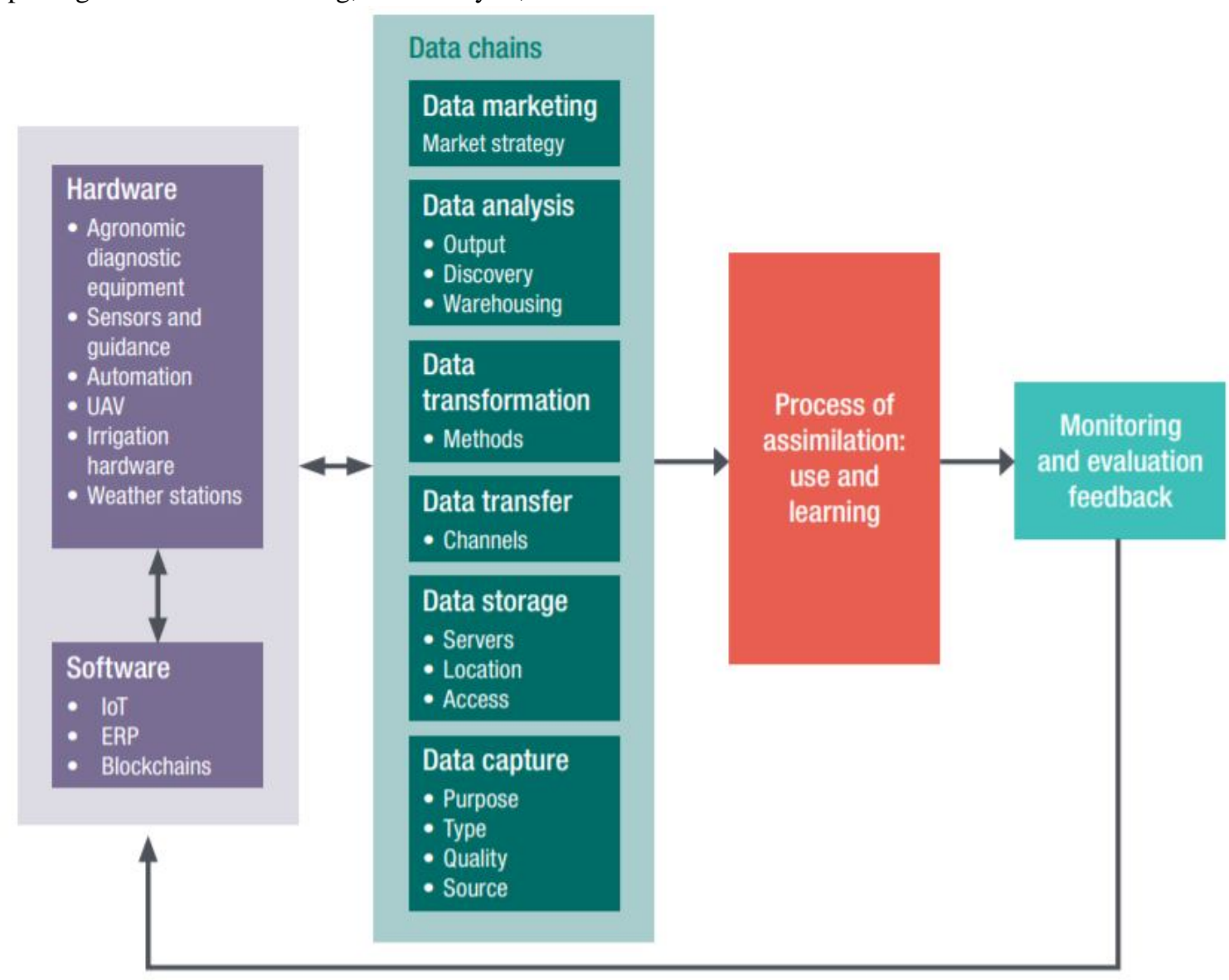

Figure 1: Building blocks of Agricultural Technology [28] 


\section{CHARACTERISTICS OF DRONES}

The significance of drones is based on futures and characteristics. However, this section is discussed in detail on the degree of autonomy, weight, size, and energy source difference.

\subsection{Degree of Autonomy}

As a result of the absence of a physical presence in guiding various flight schematics and control in a drone, it is essential to have multiple kinds of autonomy present in the drone flight control. The degree of freedom varies, and it could either be automatic or autonomous; this gives a varied difference between the ideas of autonomy. One of the characteristic features of an automated system is that it carries out pre-programmed tasks [29]. Automation also covers aspects such as automatic stabilization of flight. Self-governing systems use a pre-programmed rule set, while also seeking to deal with unanticipated situations [30]. Automated systems cannot exercise this freedom of choice. Automated systems are not a matter of choice. For uncontrolled systems, the United States Defense Department has four levels of autonomy on its roadmap [31]. A particular method that will require personnel to make all necessary decisions and analyses concerning basic drone operations is termed a fundamental autonomy level. This system has no autonomous environmental control.

Furthermore, autonomous system involves the delegation of a human being. This system can carry out several functions, regardless of human intervention and expertise. It can continue with the prescribed operations without further human input if delegated. While carefully considering essential factors that have to be noted when human intervention has been disabled ranging from the overall engine control to the various concepts and types of autonomy. A human supervised system is the third degree of autonomy. This system can accomplish several tasks with programmed certain human rights and instructions given to it. When considering this type of autonomy, the user and the programmed system get the required information to take specified actions regarding the information received. However, the case, these actions can only be initiated within the framework of the current task. A fully autonomous system is the final level of autonomy. This system receives human commands resulting in interpretation for particular tasks without further intervention from the user. A user can interfere with these tasks in the event of an emergency.

\subsection{Weight and Size}

The size and weight of a drone are other essential characteristics. [32] differentiated between the various available sizes of drones and categorize them into multiple subsections. In addition to the drone categories, Clarke adds minimum weight indicators. For fixed-wing drones, the maximum weight is at $150 \mathrm{~kg}$, and for multi-rotor, the figure stands at $100 \mathrm{~kg}$. Either light or heavy drones characterize many countries. For example, ILT distinguishes between light drones and heavy drones [33]. Light drones, fixed-wing drones, have a limit weight standing at $150 \mathrm{~kg}$ of drones while the heavy drones are $150 \mathrm{~kg}$ or more of a drone [33]. At the same time, significant improvement is being set in place to achieve drones for better public acceptance. [34] was able to differentiate between the light and heavy drones, but focusing on individual functional criteria. The primary use of big drones is for military purposes. A shift, therefore, from heavy drones to lighter drones can, thus, be observed. The categories of reference and category parameters must, therefore, be changed. Consequently, they recommend using the term heavy drones when the weight is between 20 and $150 \mathrm{~kg}$ for fixed drones, whereas multi-rotor drones are between the weight limit of 25 and $100 \mathrm{~kg}$. A light drone of up to $20 \mathrm{~kg}$ and a multi-rotor drone weighing $25 \mathrm{~kg}$ are fixed-wing drones. They propose the use of a subcategory of mini-drones when addressing light drones.

\subsection{Energy Source Difference}

When discussing the energy source of drones, there are four significant sources of energy available: traditional aircraft, battery cells, solar, and fuel cells [35]. Fuel from aircrafts being kerosene is used primarily in heavy fastener drones. The military drone Predator is an example. This particular drone has been adopted by the American military and incorporated a wide range of sensors and other ammo. When battery cells are used, it is mostly in light multi-rotor drones [32]. Lightweight drones are usually short-ranged and require lots of time to operate compared to drones that use kerosene. Often for leisure use, these drones make it more convenient for the drone to run on a rechargeable battery cell.

A fuel cell is an electrical device that can potentially change chemical energy from a fuel into electrical power. With the fuel cell, there is an efficient conversion as there is no loss in thermal and mechanical energy; this makes it relatively environmentally friendly. Currently, in drones, fuel cells are seldom used. The cell's relatively high weight can equip only fixed-wing drones with such a battery. A significant benefit of using a fuel cell is that drones can fly longer distances without being charged. The drone that uses a fuel cell, for example, has a flight time of eight hours rather than two hours [32]. In the current drone industry, drones that use solar cells are rare. Solar cell drones are mostly drones with a fixed-wing. These cells are generally suitable for many multi-rotor drones due to the low efficiency of the current solar cells. However, for 
V. Essien et al., International Journal of Emerging Trends in Engineering Research, 8(10), October 2020,7712 - 7717

small ornithopters, solar cells are appropriate. Solar cell drones caught media attention when both Google and Facebook had business deals with drone companies.

\section{APPLICATIONS OF DRONES FOR AGRICULTURE CROP MONITORING, AND RANCHING}

\subsection{Crop Monitoring}

The application of mechatronics in agriculture has become evident in recent times [37], [38]. Drones function in this category as one major essential operation. It is required at all stages during the plant's growth, from when it sprouts until when it is time to harvest. It will be challenging for particular farmers, especially those practicing commercial agriculture, to carry out surveys on their crops and do that in good times and less energy. An autonomous quadcopter UAV can be employed to carry out routine inspections of the plants on the farm. The farmer can decide to make it a weekly check or monthly, depending on his preference and the kind of crop. It functions mainly to checkmate pest infestation on plants. We have numerous challenges in Africa when it comes to growing crops. An autonomous quadcopter UAV will invariably curb some of these problems [39], [40]. It can help the farmer a particular stand of plants that are not growing correctly and, since the inspection, allows the farmer to view his field from the sky. It gives a better view and allows the farmer to better judge when determining which crop particularly needs uprooting or treatment. Most of the pesticides being used on crops are harmful and toxic to human beings and the environment when applied in excess. However, its importance in fighting pests cannot be ignored, and it still has to be used to control pests. An autonomous quadcoptor UAV will help serve for precision. Uniform application of the pesticide can also be achieved when using an autonomous quadcoptor UAV as the pesticide will only be applied to affected areas.

\subsection{Drones for Ranching (Animal Husbandry)}

This area of application in agriculture involves rearing animals for meat. In Nigeria, cattle rearing has constituted a nuisance in the country. With the nomadic practice of cattle rearing still existent in the country, it will only be proper to introduce ranching. A farmer can well have a vast expanse of land where he keeps his farm animals and deploys an autonomous quadcopter UAV to inspect the animals from time to time. The manager at the Metador cattle company J. D. Russel, implored their company has already employed drone technology in Russel ranch, and stated that with the utilization of drones at the ranch, whenever there is an emergency with any cattle, proper visualization is carried out with a drone instead of a physical presence [36].

\section{CONCLUSION}

The use of drones in agriculture is significant and can improve the overall product greatly and mostly the products gotten from specific farms. It is still gaining recognition in developing countries. In African continent, the employment of drones in agricultural and farm practices will most certainly help to exploit land resources to a great extent. With continuous breakthroughs achieved in drone technology, this only reveals the numerous potentials drones have to offer in the future. This review has been able to explore the upcoming areas, recent and future applications of drones in agriculture. The use of drones in Africa will go a long way in serving in various capacities, mostly Nigeria. Due to the constant evolution of all sectors in the world, the agricultural sector will receive a massive boost with the full integration of drones. In the long-run, farming operations will enable the farmer to cut extra costs, which would have resulted from losses through pests and diseases as well as curtail waste.

\section{ACKNOWLEDGEMENT}

The authors wish to acknowledge the financial support offered by Covenant University in the actualization of this research work for publication.

\section{REFERENCES}

1. C. Sandbrook, "The social implications of using drones for biodiversity conservation," Ambio, vol. 44, no. 4, pp. 636-647, 2015.

2. H. K. Gibbs et al., "Tropical forests were the primary sources of new agricultural land in the 1980s and 1990s," vol. 107, no. 38, pp. 1-6, 2010.

3. FAO, IFAD, and WPF, "The State of Food Insecurity in the World The multiple dimensions of food security 2013 Key messages," ROME, 2013.

4. FAO, IFAD, UNICEF, WFP, and WHO, "THE STATE OF FOOD SECURITY AND NUTRITION IN THE WORLD," ROME, 2017.

5. UNDP, "UNITED NATIONS DEVELOPMENT PROGRAMME Development choices will define the future," New York, 2019.

6. AU and NEPAD, "Comprehensive Africa Agriculture Development Programme," ROME, 2003.

7. D. Maski and V. K. Palled, "Development and evaluation of drone mounted sprayer for pesticide applications to crops," no. October, p. 8, 2017.

8. J. Primicerio et al., "A flexible unmanned aerial vehicle for precision agriculture," no. September 2016, 2012.

9. L. Merino, F. Caballero, J. R. M. Dios, and I. Maza, "An Unmanned Aircraft System for Automatic Forest Fire Monitoring and Measurement An Unmanned Aircraft System for Automatic Forest Fire Monitoring and Measurement," no. October 2014, 2012.

10. C. Yang, J. H. Everitt, J. M. Bradford, and D. E. Escobar, "MAPPING GRAIN SORGHUM GROWTH AND 
V. Essien et al., International Journal of Emerging Trends in Engineering Research, 8(10), October 2020,7712 - 7717

YIELD VARIATIONS USING AIRBORNE MULTISPECTRAL DIGITAL IMAGERY," vol. 43, no. 6, pp. 1927-1938, 2000.

11. S. Sivarajan, "Estimating Yield of Irrigated Potatoes Using Aerial and Satellite Remote Sensing," 2011.

12. U. M. R. Mogili and B. B. V. L. Deepak, "Review on Application of Drone Systems in Precision Agriculture," Procedia Comput. Sci., vol. 133, pp. 502-509, 2018.

13. A. Lebedev, "Design and Implementation of a 6DOF Control System for an Autonomous Quadrocopter," Luleå University of Technology, 2013.

14. A. Otto, N. Agatz, J. Campbell, and B. Golden, "Optimization approaches for civil applications of unmanned aerial vehicles (UAVs) or aerial drones: A survey," no. February, pp. 1-48, 2018.

15. P. N. Patel, M. A. Patel, R. M. Faldu, and Y. R. Dave, "Quadcopter for Agricultural Surveillance," vol. 3, no. 4, pp. 427-432, 2013.

16. W. Qin, X. Xue, S. Zhang, W. Gu, and B. Wang, "Droplet deposition and efficiency of fungicides sprayed with small UAV against wheat powdery mildew," vol. 11, no. 2, pp. 27-32, 2018.

17. L. Qi, Z. Yanliang, L. Qi, and Z. Wei, "Design and test of a six-rotor unmanned aerial vehicle (UAV) electrostatic spraying system for crop protection," no. November 2017, 2018.

18. S. K. Phang, K. Li, K. H. Yu, B. M. Chen, and T. H. Lee, "Systematic Design and Implementation of a Micro Unmanned Quadrotor System," vol. 2, no. 2, pp. 121-141, 2014.

19. S. Bouabdallah, "Design and Control of quadrotors with application to autonomous flying design and control of quadrotors with application to autonomous flying," no. January 2007, 2015.

20. G. Voicu, "Research on the use of drones in precision agriculture RESEARCH ON THE USE OF DRONES IN PRECISION," no. January 2015, 2019.

21. N. G. A, E. M. A, and J. G. B, "PHOTOGRAMMETRIC MAPPING USING UNMANNED AERIAL VEHICLE N. Graça," vol. XL, no. November, pp. 17-20, 2014.

22. F. Marinello, A. Pezzuolo, A. Chiumenti, and L. Sartori, "Technical analysis of unmanned aerial vehicles (drones) for agricultural applications," no. May, 2016.

23. P. Psirofonia, V. Samaritakis, P. Eliopoulos, and I. Potamitis, "Use of Unmanned Aerial Vehicles for Agricultural Applications with Emphasis on Crop Protection: Three Novel Case-studies," no. February, 2017.

24. E. J. Van Henten and F. Technology, "Autonomous Unmanned Aerial Vehicles for Agricultural Applications," pp. 6-10, 2014.

25. R. Kellermann, T. Biehle, and L. Fischer, "Drones for parcel and passenger transportation: A literature review is, " Transp. Res. Interdiscip. Perspect., vol. 4, p. 100088, 2020.

26. F. M. Makini et al., "The Status of ICT Infrastructure, Innovative Environment and ICT4AG Services in
Agriculture, Food and Nutrition in Kenya," vol. 5, no. March, 2020.

27. H. M. Toonen and S. R. Bush, "The digital frontiers of fisheries governance: fish attraction devices, drones and satellites," vol. 7200, 2020.

28. A. Krishnan, K. Banga, and M. Mendez-parra, "Disruptive technologies in agricultural value chains Insights from East Africa," no. 1, pp. 1-60, 2020.

29. M. Burston, R. Sabatini, A. Gardi, and R. Clothier, "Reverse Engineering of a Fixed Wing Unmanned Aircraft 6 - DoF Model Based on Laser Scanner Measurements," no. May, 2014.

30. A. Chialastri, Automation in Aviation. ROME, 2012.

31. USDOD, UNMANNED SYSTEMS INTEGRATED ROADMAP. 2013.

32. B. Custers, "Technology in policing: Experiences, obstacles and police needs," Comput. Law Secur. Rev., vol. 28, no. 1, pp. 62-68, 2012.

33. Civil Aviation Authority, "Informatiebulletin lichte onbemande luchtvaartuigen UAS - unmanned aircraft systems," Den Haag, 2013.

34. F. Marinello, A. Bono, and A. Pezzuolo, "Determination of local nitrogen loss for exploitation of sustainable precision agriculture: approach description," no. June, 2017.

35. E. Salamí, C. Barrado, and E. Pastor, "UAV Flight Experiments Applied to the Remote Sensing of Vegetated Areas," pp. 11051-11081, 2014.

36. Moseman, Andrew "How drones will revolutionalize ranching" June, 2018.

37. Azeta, J., Bolu, C. A., Hinvi, D., Abioye, A. A., Boyo, H., Anakhu, P., \& Onwordi, P. (2019). An Android Based Mobile Robot for Monitoring and Surveillance. Procedia Manufacturing, 35, 1129-1134.

38. Azeta, J., Bolu, C. A., Alele, F., Daranijo, E. O., Onyeubani, P., \& Abioye, A. A. (2019, December). Application of Mechatronics in Agriculture: A review. In Journal of Physics: Conference Series (Vol. 1378, No. 3, p. 032006). IOP Publishing.

39. Azeta, J., Ishola, F., Akinpelu, T., Bolu, C., Dirisu, J., Fajobi, M. A., \& Salawu, E. Y. (2019). An Experimental Evaluation of LTA on the performance of a drone. Procedia Manufacturing, 35, 1135-1140.

40. Azeta, J., Ishola, F., Akinpelu, T., Dirisu, J. O., Okokpujie, I. P., \& Ibhadode, O. (2019). Performance Evaluation of Developed Mathematical Models of Hot Air Balloon for Drone Application. Procedia Manufacturing, 35, 1073-1078. 